\title{
Thrombin regulates the ability of Schwann cells to support neuritogenesis and to maintain the integrity of the nodes of Ranvier
}

\author{
Elena Pompili, ${ }^{1}$ Viviana Ciraci, ${ }^{2}$ Stefano Leone, ${ }^{3}$ Valerio De Franchis, ${ }^{1}$ Pietro Familiari, ${ }^{4}$ Roberto Matassa, ${ }^{1}$ \\ Giuseppe Familiari, ${ }^{1}$ Ada Maria Tata, ${ }^{5,6}$ Lorenzo Fumagalli, ${ }^{1}$ Cinzia Fabrizi ${ }^{1}$ \\ ${ }^{1}$ Department of Anatomy, Histology, Forensic Medicine and Orthopedics, Sapienza University of Rome, Italy \\ ${ }^{2}$ Institute for Medicines (iMed.ULisboa), Faculty of Pharmacy, University of Lisboa, Portugal \\ ${ }^{3}$ Department of Biology, Roma Tre University, Rome, Italy \\ ${ }^{4}$ Department of Neuroscience, Mental Health and Sense Organs NESMOS, Sapienza University of Rome, Italy \\ ${ }^{5}$ Department of Biology and Biotechnology Charles Darwin, Sapienza University of Rome, Italy \\ ${ }^{6}$ Research Center in Neurobiology, Sapienza University of Rome, Italy
}

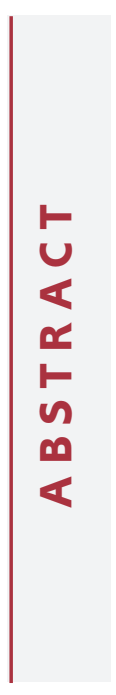

Schwann cells (SC) are characterized by a remarkable plasticity that enables them to promptly respond to nerve injury promoting axonal regeneration. In peripheral nerves after damage SC convert to a repair-promoting phenotype activating a sequence of supportive functions that drive myelin clearance, prevent neuronal death, and help axon growth and guidance. Regeneration of peripheral nerves after damage correlates inversely with thrombin levels. Thrombin is not only the key regulator of the coagulation cascade but also a protease with hormone-like activities that affects various cells of the central and peripheral nervous system mainly through the protease-activated receptor 1 (PAR1). Aim of the present study was to investigate if and how thrombin could affect the axon supportive functions of SC. In particular, our results show that the activation of PAR1 in rat SC cultures with low levels of thrombin or PAR1 agonist peptides induces the release of molecules, which favor neuronal survival and neurite elongation. Conversely, the stimulation of SC with high levels of thrombin or PAR1 agonist peptides drives an opposite effect inducing SC to release factors that inhibit the extension of neurites. Moreover, high levels of thrombin administered to sciatic nerve ex vivo explants induce a dramatic change in SC morphology causing disappearance of the Cajal bands, enlargement of the Schmidt-Lanterman incisures and calcium-mediated demyelination of the paranodes. Our results indicate thrombin as a novel modulator of SC plasticity potentially able to favor or inhibit SC pro-regenerative properties according to its level at the site of lesion.

Key words: Protease-activated receptor 1; glia; rat; peripheral nervous system.

Correspondence: Dr. Stefano Leone, Department of Biology, Roma Tre University, Viale Guglielmo Marconi 446, 00146 Rome, Italy. E-mail: stefano.leone@uniroma3.it

Contributions: EP, VC, contributed equally to this study; CF, EP, VC, SL, VDF, conceived, planned and performed the experiments; LF, supervised the project; CF, EP, wrote the article; AMT, performed sciatic nerve dissection and prepared Schwann cell cultures. All authors discussed the results, have read and approved the final version of the manuscript and agreed to be accountable for all aspects of the work.

Conflict of interest: The authors reported no potential conflict of interest.

Ethical Approval: All procedures involving animals were carried out in accordance with the guidelines of the European Communities Council Directive (86/609/EEC of 24 November 1986) and the Italian National law DL/116/92. All methods used were carried out in accordance with guidelines of the protocols n. 7FF2C.6.EXT.96 that has been approved by the Ministry of Health (AMT, Aut. N. 1184/2016-PR 16/12/2016). 


\section{Introduction}

The strong regenerative potential of peripheral nerves is mainly due to the ability of Schwann cells (SC) to convert to a repairpromoting phenotype, which encourages axon growth (for a recent review see ${ }^{1}$ ). Unfortunately, nerve stumps distal to transection maintain full or mildly reduced capacity for supporting regeneration only for about 1 month. Fading of the SC repair phenotype occurs in chronic denervation and is amplified in aging. ${ }^{2-4}$

The lesion of a peripheral nerve is accompanied by a local dramatic increase in thrombin activity respect to the uninjured control. ${ }^{5,6}$ Circulating concentration of prothrombin in normal subjects ranges from $700 \mathrm{nM}$ to $1.7 \mu \mathrm{M}^{7}$ It is also worth noting that both thrombin and the extrinsic pathway FX/FXa are locally generated in sciatic nerve. ${ }^{8}$ In the peripheral nervous system (PNS), low concentrations of thrombin were found to enhance the regeneration of mouse peripheral nerve after its crushing, ${ }^{9}$ while high concentrations had deleterious effects. ${ }^{10}$ Accordingly, in the central nervous system (CNS) thrombin is neuroprotective against ischemia at low concentration but causes degeneration at high concentration. ${ }^{11}$ Thrombin is the key effector protease of the coagulation cascade mediating hemostasis, thrombosis, and inflammatory responses to vascular injury predominantly through the proteaseactivated receptor 1 (PAR1). ${ }^{12}$ It is well known that SC primary cultures release factors that promote the viability and neuritogenesis of neuronal cells. ${ }^{13}$ In this connection, our previous data indicate that the activation of PAR1 by low levels of specific agonist peptides in SC cultures enhances their ability to release molecules (such as decorin and macrophage migration inhibitory factor, MIF) that favor neuronal survival and neurite extension. ${ }^{14}$ PAR1 is the main thrombin receptor and acts as a biosensor translating the dynamic changes in the proteolytic microenvironment into cellular responses. It is activated when thrombin cleaves its N-terminal exodomain at a specific site. This cleavage event unmasks a new $\mathrm{N}$-terminus that then serves as a tethered ligand that binds intramolecularly to the receptor effecting transmembrane signaling. A synthetic agonist peptide (PAR1 AP) with a sequence corresponding to the tethered ligand is able to stimulate PAR 1 signalling without the need of proteolytic activation. ${ }^{1}$ PAR1 is a G proteincoupled receptor (GPCR) and its signaling is transduced via activation of phospholipase C (PLC), generation of inositol trisphosphate (IP3) and diacylglycerol (DAG), consecutive $\mathrm{Ca}^{2+}$ release from intracellular stores, and protein kinase $\mathrm{C}(\mathrm{PKC})$ activation. Unlike classic GPCRs, which are internalized and recycled back to the cell surface after agonist stimulation, activated PAR1 is internalized and sorted from endosomes to lysosomes and degraded. Internalization and lysosomal sorting is critical for terminating activated PAR1 signaling. ${ }^{16}$ PAR 1 is expressed within the blood vascular system and throughout the CNS, predominantly in neurons, microglia, astrocytes, and oligodendrocytes. ${ }^{11,17}$ PAR1 agonists mediate oligodendrogliopathy ${ }^{18}$ and targeting this receptor genetically or pharmacologically reduces its dysmyelinating effects. ${ }^{19}$ In the PNS, PAR1 is present on the SC plasma membrane and particularly concentrated at the level of the non-compacted SC microvilli of the nodes of Ranvier. ${ }^{14,20}$

In the present study we compared the ability of low and high levels of thrombin in modulating the SC neurotrophic properties in cultures and the integrity of the nodes of Ranvier in sciatic nerve ex vivo explants. To note high levels of thrombin or PAR1 AP directly applied to rat sciatic nerve have been demonstrated to produce a rapid conduction block. ${ }^{20}$ Our data show that high and low levels of thrombin displayed completely different actions inhibiting the former and favoring the latter the ability of SC of supporting neuritogenesis. In addition, thrombin at high levels determined a $\mathrm{Ca}^{2+}$-dependent paranodal demyelination of sciatic nerve fibers.

\section{Materials and Methods}

\section{Materials}

Collagenase type I, donkey serum, Hanks' Balanced Salt Solution (HBSS), hirudin, mouse monoclonal anti-S100b antibody (AB_477499), poly-D-lysine hydrobromide, poly-L-ornithine hydrobromide, Sudan black B, thapsigargin, thrombin, $0.25 \%$ trypsin were from Sigma-Aldrich, Milan, Italy.

Advanced Dulbecco's Modified Eagle Medium (Advanced DMEM), fetal bovine serum, Fluo-4 AM (stock solution $1 \mathrm{mM}$ in DMSO), glycine, horse serum, N,N'-[1,2-ethanediylbis(oxy-2,1phenylene)]bis[N-[2-[(acetyloxy)methoxy]-2-oxoethyl]], bis[(acetyloxy)methyl] ester (BAPTA-AM; stock solution $5 \mathrm{mM}$ in DMSO) were from Invitrogen, Monza, Italy.

Phosphate buffer saline (PBS) $\left(0.1 \mathrm{~g} / \mathrm{L} \mathrm{Ca}^{2+}\right.$ Chloride, $0.2 \mathrm{~g} / \mathrm{L}$ Potassium Chloride, $0.2 \mathrm{~g} / \mathrm{L}$ Potassium Dihydrogen Phosphate, 0.1 g/L Magnesium Chloride Hexahydrate, 8 g/L Sodium Chloride, $2.1716 \mathrm{~g} / \mathrm{L}$ Disodium Phosphate Heptahydrate) was from Corning.

The PAR1 activating peptide (PAR1 AP) TFLLR-NH2 was from Bachem AG, Bubendorf, Switzerland.

Rabbit polyclonal antibody anti PAR1 (bs-0828R) was from Bioss Antibodies Inc., Woburn, MA, USA.

SCH79797 (PAR1 selective antagonist) (stock solution $10 \mathrm{mM}$ in ethanol) was from Tocris Bioscience, Bristol, UK

Dylight 549-labelled anti-rabbit IgG and donkey AlexaFluor 488-labelled anti-mouse IgG were from Jackson ImmunoResearch Laboratories, West Grove, PA, USA.

Affinity-purified goat anti-mouse IgG, Vectashield mounting solution were from Vector Laboratories, Burlingame, CA, USA.

\section{Preparation and treatments of primary Schwann cell cultures}

Schwann cells were isolated from the sciatic nerves of male and female newborn Wistar rats and cultured as previously described, ${ }^{21,22}$ with some modifications. All procedures involving animals were carried out in accordance with the guidelines of the European Communities Council Directive (86/609/EEC of 24 November 1986) and the Italian National law DL/116/92. All methods used were carried out in accordance with guidelines of the protocols n. 7FF2C.6.EXT.96 that has been approved by the Ministry of Health (AMT, Aut. n. 1184/2016-PR 16/12/2016). Briefly, the bilateral sciatic nerves were removed from 2- to 3-dayold rats, minced with fine dissecting scissors into fragments, digested twice with $0.25 \%$ trypsin and $1 \mathrm{mg} / \mathrm{mL}$ collagenase type I in Advanced DMEM at $37^{\circ} \mathrm{C}$ for $30 \mathrm{~min}$. Contaminating fibroblasts were removed by immunopanning. Briefly tissue culture plates were precoated with affinity-purified goat anti-mouse IgG and then incubated with OX-7 hybridoma culture supernatant containing anti-Thyl IgG, which binds the cell surface molecule Thy1.1 expressed on fibroblasts. Non-adherent cells were plated at $500-1000$ cells $/ \mathrm{mm}^{2}$ in petri dishes of $5 \mathrm{~cm}$ diameter (Falcon) precoated with poly-D-lysine hydrobromide. Cells were cultured in Advanced DMEM supplemented with $10 \%$ fetal bovine serum. Cells were incubated at $37^{\circ} \mathrm{C}$ in a humidified $5 \% \mathrm{CO}_{2}$ atmosphere and medium was changed every three days. The cell preparation consisted of $95 \%$ Schwann cells, as assessed by immunocytochemistry with anti-S100b antibody. Schwann cells were plated in 6well plates $\left(7 \times 10^{5}\right.$ cells/well $)$ in $2 \mathrm{~mL}$ of Advanced DMEM supplemented with $10 \%$ fetal bovine serum. After $24 \mathrm{~h}$ cells were washed three times in HBSS and then treated for $48 \mathrm{~h}$ in advanced DMEM serum-free medium with thrombin $(1,10,100 \mathrm{U} / \mathrm{mL})$, the PAR1 activating peptide (PAR1 AP) $(1,10,100 \mu \mathrm{M})$, hirudin $(10,100$ $\mathrm{U} / \mathrm{mL}), \mathrm{SCH} 79797(1 \mu \mathrm{M})$ alone or in combination. The PAR1 specific inhibitor SCH79797 was added 5 min before PAR1 AP. 


\section{PC12 neurite outgrowth and survival assays}

The conditioned medium (CM) from Schwann cells was recovered, spun, supplemented with $5 \%$ fetal bovine serum and $10 \%$ horse serum and added to rat pheochromocytoma PC12 cells (ECACC) for assessing neurite outgrowth. In fact, previously published data indicate that Schwann cells release factors promoting cell survival and neurite outgrowth of PC12 cells. ${ }^{13,14}$

PC12 cells were grown on coverslips precoated with poly-Lornithine hydrobromide in 24-well tissue culture plates. Cells were seeded at low density $\left(5 \times 10^{3}\right.$ cells/well) to avoid contact inhibition of neuritogenesis at higher densities. PC12 treated with nerve growth factor (NGF; $50 \mathrm{ng} / \mathrm{mL}$ ) were used as positive controls. Medium was replaced every three days and after a week, PC12 cells were stained with hematoxylin and imaged with Nikon light microscope (Eclipse E600; Nikon Instruments SpA, Florence, Italy). The number of undifferentiated and neurite-extending cells was determined by visual examination of the field and expressed as the percentage of the total cells. Cells with neurites were defined as cells that possessed at least one neurite with a length equal or longer than the cell body diameter $(12 \mu \mathrm{m}$ is the mean diameter of the control non-differentiated cells); 50-100 cells were assessed in one experiment, and data are the means $\pm \mathrm{SE}$ of three experiments.

For cell survival assays PC12 cells were seeded in 96-well plates $\left(2 \times 10^{4}\right.$ cells/well $)$ and after $24 \mathrm{~h}$ from seeding they were cultured with the serum-free conditioned medium from Schwann cells treated with thrombin $(10,100 \mathrm{U} / \mathrm{mL})$ or PAR1 AP $(10,100 \mu \mathrm{M})$ as mentioned above. Conditioned medium was replaced every three days and after a week MTT assay was used to evaluate cell viability. The MTT test measures the ability of living cells to reduce MTT [3-(4,5-dimethylthiazol-2-yl)-2,5-diphenyltetrazolium bromide] into formazan crystals by the activity of mitochondrial dehydrogenases. MTT assay was performed essentially as described by Fabrizi et al. ${ }^{23}$ Briefly, $10 \mu \mathrm{L}$ of MTT solution (5 $\mathrm{mg} / \mathrm{mL}$ ) was added to each well and the incubation was continued for $3 \mathrm{~h}$. Lysis buffer was prepared by dissolving $40 \%$ (w/v) SDS in deionized water, after adding an equal volume of N,N dimethylformamide, and the $\mathrm{pH}$ was adjusted to 4.7. After a 3-h incubation with MTT, $100 \mu \mathrm{L}$ of the lysis buffer was added to each well and the absorbance read at $570 \mathrm{~nm}$ on a microplate reader (Model 550 Microplate Reader, BioRad Laboratories, Hercules, CA, USA). The relative cell viability (\%) was expressed as a percentage relative to the untreated control cells.

In addition, cell viability was also assessed in the same samples by measuring the release of lactate dehydrogenase (LDH) in the culture medium by the Cytotoxicity Detection Kit (Roche, Mannheim, Germany) as previously described. ${ }^{24}$

\section{Measurement of $\left[\mathrm{Ca}^{2+}\right]_{i}$ mobilization}

Schwann cells seeded onto poli-L-lysine precoated chamber slides (Ibidi, Martinseried, Germany) were loaded with $1 \mu \mathrm{M}$ of the cytosolic $\mathrm{Ca}^{2+}$ indicator Fluo- $4 \mathrm{AM}$ at $37^{\circ} \mathrm{C}, 5 \% \mathrm{CO}_{2}$ for 15 min in PBS pH 7.4 containing $25 \mathrm{mM}$ glucose and $1 \%$ bovine albumin. After dye loading, cells were washed three times and then images were recorded using confocal microscope TCS-SP5 (Leica Microsystems, Heidelberg, Germany). Fluorescence intensity vs. time was quantified with LAS-X analysis software (Leica Microsystems) and expressed as $\Delta \mathrm{F} / \mathrm{F}_{0}$. The mean fluorescence value of all cells in one field measured at the start of the experiment is $\mathrm{F}_{0}$ and $\mathrm{F}$ is the fluorescence intensity recorded in the same field as the experiment runs.

\section{Ex vivo nerve explants}

Sciatic nerves were rapidly removed from female adult Wistar rats (200-250 g) and cut in 4-mm-long segments. The pieces of sciatic nerve were incubated free-floating in advanced DMEM at $37^{\circ} \mathrm{C}$ in $5 \% \mathrm{CO}_{2} / 95 \%$ humidified air atmosphere and treated for 30 min, $1 \mathrm{~h}$ and $2 \mathrm{~h}$ with: $1,10,100 \mathrm{U} / \mathrm{mL}$ of thrombin; $1,10,100 \mu \mathrm{M}$ PAR1 AP; 10, $100 \mathrm{U} / \mathrm{mL}$ hirudin; $1 \mu \mathrm{M} \mathrm{SCH79797} \mathrm{(5} \mathrm{min} \mathrm{pre-}$ treatment); $1 \mu \mathrm{M}$ BAPTA-AM (30 min pre-treatment); $100 \mathrm{nM}$ thapsigargin alone or in combinations. At the end of the procedure samples were fixed for $30 \mathrm{~min}$ at room temperature (RT) with $4 \%$ paraformaldehyde in $0.12 \mathrm{M}$ phosphate buffer, $\mathrm{pH} 7.4$, washed in PBS and teased on positively charged glass slides. For immunofluorescence staining, teased fibers were blocked with $10 \%$ donkey serum containing $0.2 \%$ gelatin and $0.3 \%$ Triton X-100 for $1 \mathrm{~h}$ at RT and then incubated overnight at $4{ }^{\circ} \mathrm{C}$ with rabbit anti-PAR1 (diluted 1:100) and mouse anti-S100b antibodies (diluted 1:1000). After washings with PBS, nerve preparations were incubated with donkey Dylight 549-labelled anti-rabbit IgG (diluted 1:400) and donkey AlexaFluor 488-labelled anti-mouse IgG (diluted 1:400). Negative controls were done by omission of the first antibody or by replacing the primary antibody with an equivalent amount of Igs purified from preimmune sera. After a final wash with PBS, the preparations were overlaid with coverslips using Vectashield mounting solution and imaged with confocal microscope TCS-SP5 (Leica Microsystems, Heidelberg, Germany). For Sudan black B staining, teased fibers were immersed in $0.1 \%$ Sudan black B diluted in $70 \%$ ethanol for 20 min at RT. Slides were then washed three times for 5 min each in PBS containing $0.02 \%$ Tween 20. After a final wash with PBS, the preparations were overlaid with coverslips using Vectashield mounting solution and imaged with Nikon light microscope (Eclipse E600; Nikon Instruments SpA).

\section{Variable pressure-scanning electron microscope}

Hydrated teased fibers from ex vivo nerve explants were observed using a variable pressure-scanning electron microscope (VP-SEM) (Hitachi SU-3500). VP-SEM combined with Peltier coolstage control optimally allowed high-resolution imaging of hydrated specimens under varying pressure conditions, limiting water vapour loss through control of stage temperature. Hydrated samples prepared as described in section above were directly observed on positively charged glass slides without conductive coating. A thin film of distilled water was deposited onto hydrated samples at RT to limit water-loss during low vacuum procedures. By appropriate control of chamber pressure and cooling temperature, particular attention has been paid to avoid the formation of collapsed surface of the Ranvier nodes. All samples were observed at an accelerating voltage of $6 \mathrm{kV}$ with working distance between 5 and $6.2 \mathrm{~mm}$ and the correlative pressure/temperature were stabilized at $50 \mathrm{~Pa} /-25^{\circ} \mathrm{C}$ before.

By VP-SEM technique alterations in morphology and structure of the nodes were observed in their native hydrated state to assess minimal conformational changes of the nerves. Respect to conventional scanning electron microscope (SEM), VP-SEM is less timeconsuming and less prone to create artifacts during processing.

\section{Statistics}

All experiments were performed in triple if not otherwise stated and reproduced three times. Statistical analyses were conducted using GraphPad Prism version 4.00 software. Comparisons were analysed using one-way ANOVA with Bonferroni-corrected $t$-test. A minimum statistical value $\mathrm{P}<0.05$ was considered significant.

\section{Results}

As mentioned above, $\mathrm{SC}$ in culture release factors that enhance neuronal survival and neurite extension ${ }^{13}$. Consistently with those previous reports, in neuronal PC12 cell line only $21 \pm 4 \%$ of the untreated cells bore neurites at 7 days while this percentage 
increased to $40 \pm 3 \%$ after addition of the conditioned medium of SC primary cultures (CM-SC). NGF used as positive control led the percentage of $\mathrm{PC} 12$ cells bearing neuritis to $88 \pm 9 \%$ (Figure 1A). We have previously shown that the neurotrophic properties of SC primary cultures are augmented when PAR1 is activated by low levels of specific agonist peptides (PAR1 AP). ${ }^{14}$ Here we broaden those previous results expanding the range of concentrations of PAR1 AP and using also thrombin which is the main PAR1 natural ligand. Thus, following the same procedure of our previous paper $^{14}$, SC were treated with thrombin $(1,10,100 \mathrm{U} / \mathrm{mL})$ and PAR1 AP $(1,10,100 \mu \mathrm{M})$. After $48 \mathrm{~h} \mathrm{CM}-\mathrm{SC}$ was transferred to $\mathrm{PC} 12$ cells and neurite elongation was evaluated after 7 days. No difference in neurite extension respect to controls was observed using $1 \mu \mathrm{M}$ PAR1 AP or $1 \mathrm{U} / \mathrm{mL}$ thrombin (not shown). Conversely, CM obtained from SC treated with $10 \mu \mathrm{M}$ PAR1 AP or $10 \mathrm{U} / \mathrm{mL}$ of thrombin increased the percentage of PC12 cells bearing neurites respect to controls (Figure $1 \mathrm{~B}, \mathrm{C}$ ). These results are in line with our previous data. ${ }^{14}$ When we raised the level of the PAR1 agonists we observed a completely different result. In fact, CM obtained from SC treated with $100 \mathrm{U} / \mathrm{mL}$ of thrombin or 100 $\mu \mathrm{M}$ PAR1 AP determined a reduction in the number of PC12 cells bearing neurites respect to controls (Figure $1 \mathrm{~B}, \mathrm{C}$ ). Thrombin was inhibited by hirudin which occludes both the thrombin active site and exosite I (fibrinogen and PAR1 recognition site) (Figure 1B). Similarly the PAR1 specific inhibitor SCH79797 abolished the effect of the PAR1 AP- treatment (Figure 1C).

The viability of PC12 cells was evaluated by MTT test in order to check if thrombin or PAR1 AP treatments could determine the release from $\mathrm{SC}$ of cytotoxic molecules. No difference in cell survival was measured in $\mathrm{PC} 12$ cells receiving $\mathrm{CM}$ from $\mathrm{SC}$ treated with high levels of thrombin $(100 \mathrm{U} / \mathrm{mL})$ and PAR1 AP $(100 \mu \mathrm{M})$ (Figure 2). The same samples were tested for LDH release and no statistically significant differences were measured respect to controls (not shown). Conversely, CM from SC treated with low levels of thrombin $(10 \mathrm{U} / \mathrm{mL})$ and PAR1 AP $(10 \mu \mathrm{M})$ slightly increased PC12 cell viability consistently with our previous data. ${ }^{14}$

PAR1 is a GPCR and its activation is known to determine a rapid and transient rise in intracellular $\mathrm{Ca}^{2+}$ concentration. ${ }^{16} \mathrm{In} \mathrm{SC}$ by increasing the concentration of thrombin from 10 to $100 \mathrm{U} / \mathrm{ml}$, we observed a parallel transient increase in intracellular $\mathrm{Ca}^{2+} \mathrm{lev}$ els (Figure 3 A,B). A rapid rise in cytosolic $\mathrm{Ca}^{2+}$ levels was also obtained using PAR1 AP (not shown). In order to check if the ability of thrombin in modifying SC neurotrophic properties could be calcium-mediated we used the intracellular $\mathrm{Ca}^{2+}$ chelator BAPTA-AM. When this compound was administered to SC it reverted the effect of both high and low levels of thrombin (Figure 3C). As mentioned above, the main thrombin receptor PAR1 is well expressed on the SC plasma membrane. While not being evenly distributed, it appears concentrated at the level of the nodes of Ranvier. ${ }^{14,20}$

In order to explore whether the activation of the thrombin/PAR1 pathway could affect the SC/axon interaction in nerve fibers, we moved to ex vivo explants of sciatic nerve where the structure of the nodes of Ranvier are preserved.

Nerve explants were cultured with different concentrations of thrombin $(1,10,100 \mathrm{U} / \mathrm{mL})$ or PAR $1 \mathrm{AP}(1,10,100 \mu \mathrm{M})$ for $30 \mathrm{~min}$,
A

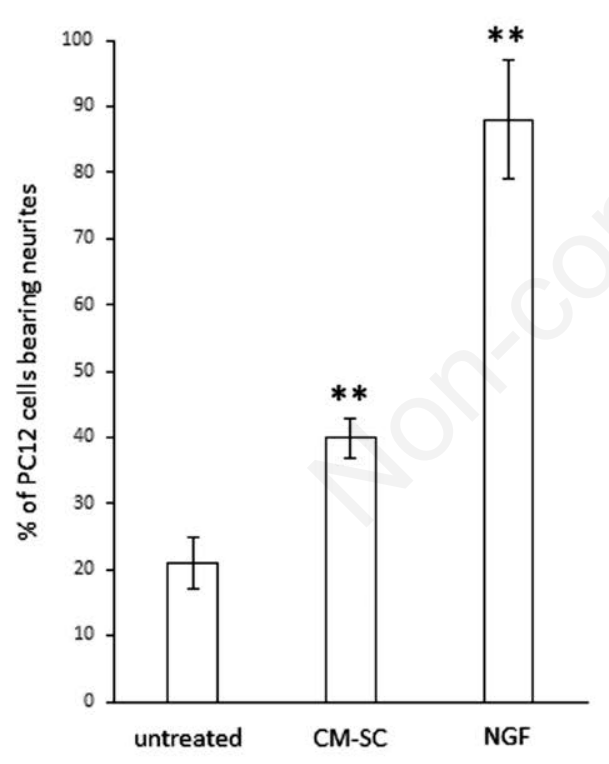

B

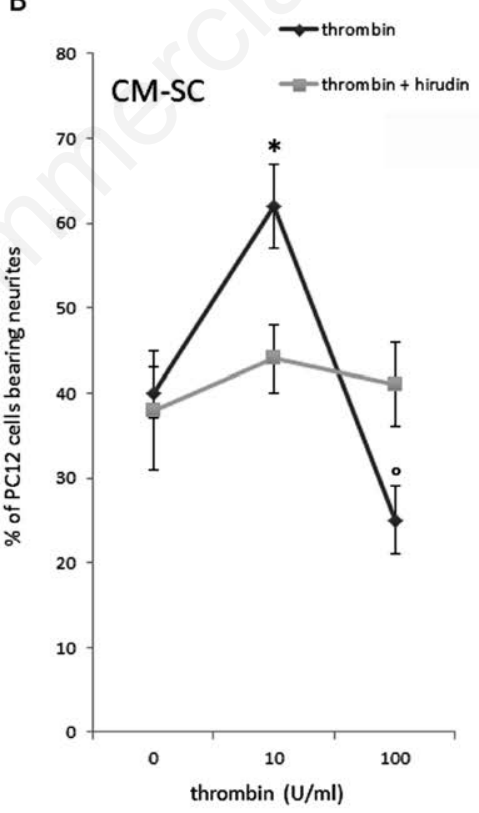

C

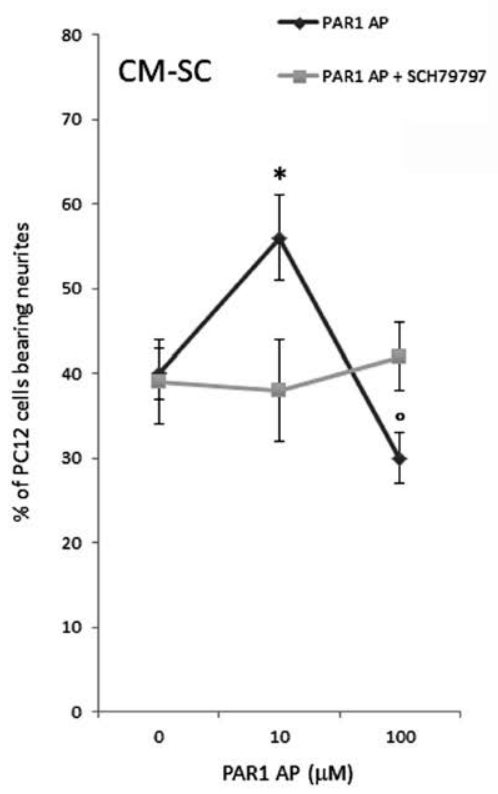

Figure 1. The conditioned medium from Schwann cells (CM-SC) stimulated with high or low levels of thrombin (or PAR1 AP) differently affects PC12 neurite outgrowth. A) PC12 cells were left untreated, treated with the culture medium from Schwann cells (CM-SC) or treated with NGF for 7 days. B) PC12 cells were exposed for 7 days to the conditioned medium (CM-SC) from untreated Schwann cells (ctrl) or from Schwann cells treated with: $10 \mathrm{U} / \mathrm{mL}$ thrombin; $100 \mathrm{U} / \mathrm{mL}$ thrombin; $10 \mathrm{U} / \mathrm{mL}$ hirudin $+10 \mathrm{U} / \mathrm{mL}$ thrombin; 100 $\mathrm{U} / \mathrm{mL}$ hirudin $+100 \mathrm{U} / \mathrm{mL}$ thrombin; $100 \mathrm{U} / \mathrm{mL}$ hirudin alone; when SC were treated with $10 \mathrm{U} / \mathrm{mL}$ of thrombin their ability to promote neurite extension of PC12 was enhanced respect to the untreated SC while it was reduced with thrombin at $100 \mathrm{U} / \mathrm{mL}$; thrombin effect was inhibited by hirudin. C) PC12 cells were exposed for 7 days to the conditioned medium (CM-SC) from untreated Schwann cells (ctrl) or from Schwann cells treated with 10, $100 \mu$ M PAR1 AP alone or in combination with $1 \mu$ M SCH79797; When SC were treated with $10 \mu \mathrm{M}$ PAR1 AP their ability to promote neurite extension of PC12 was enhanced respect to the untreated SC while it was reduced with PAR1 AP at $100 \mu \mathrm{M}$; PAR1 AP was blocked by the PAR1 inhibitor SCH79797; the percentage of neurite-bearing cells was calculated from 5 random fields per well, and the data are expressed as a mean percentage of 6 wells. Data are presented as mean $\pm \mathrm{SEM} .{ }^{\circ} \mathrm{P} \leq \mathbf{0 . 0 5} ;{ }^{*} \mathrm{P} \leq \mathbf{0 . 0 1}$ respect to $\mathrm{ctrl} ;{ }^{* *} \mathrm{P} \leq \mathbf{0 . 0 0 1}$ respect to untreated. 
$1 \mathrm{~h}$ and $2 \mathrm{~h}$. Then, nerve fibers were fixed, teased and stained for PAR1 and the SC cytoplasmic marker S100b. In untreated nerve explants PAR1 appeared mainly localized at the level of the nodes while after $2 \mathrm{~h}$ of treatment with $100 \mathrm{U} / \mathrm{mL}$ of thrombin it became more diffuse and scattered respect to the controls (Figure 4). To note, together with PAR1, also the distribution of S100b was considerably altered by thrombin treatment. In particular, in untreated nerve fibers S100b labeled the characteristic network of anastomosing, cytoplasmic channels known as Cajal bands (Figure 5 A,B) and the SchmidtLanterman incisures (SLI), another SC cytoplasmic compartment (Figure $5 \mathrm{C}$ ). The treatment with 1 and $10 \mathrm{U} / \mathrm{mL}$ of thrombin (or 1 and $10 \mu \mathrm{M}$ of PAR1 AP) did not modify the morphology of the fibers respect to the untreated controls up to $2 \mathrm{~h}$ (not shown). Conversely, in fibers treated for $2 \mathrm{~h}$ with $100 \mathrm{U} / \mathrm{mL}$ of thrombin (or $100 \mu \mathrm{M}$ PAR1 AP, not shown) we observed a completely different distribution of the S100b staining characterized by the almost complete disappearance of the Cajal bands (Figure $5 \mathrm{D}, \mathrm{E}$ ) and the marked dilation of the SLI (Figure 5F).

In order to analyze if these changes in the cytoplasmic compartments of SC corresponded to any alteration in myelin distribution, we labeled myelin by Sudan black staining. By this method we observed that nerve fibers treated with high concentrations of thrombin or PAR1 AP (100 U/mL and $100 \mu \mathrm{M}$, respectively) were characterized by an increased paranodal demyelination respect to controls (Figure 6A, Table 1). Demyelination at the level of the paranodes could also be observed at low percentage in untreated controls and tended to increase with the time in culture $(5 \pm 3 \%$ at $30 \mathrm{~min}, 8 \pm 2 \%$ at $1 \mathrm{~h}$ and $12 \pm 4 \%$ at $2 \mathrm{~h}$ ). Alterations in the morphology and structure of the nodes were analyzed in more detail by electron microscopy. In particular, nerve fibers from ex vivo sciatic nerve samples were directly observed using a VP-SEM, which operates in a wet mode with no need of desiccation and coating. Nerve fibers treated with high levels of thrombin or PAR1 AP and analyzed by electron microscopy showed an evident displacement of the $\mathrm{SC}$ at the nodes that consequently appeared elongated (Figure 6B). No alteration in the morphology of the nodes was observed with 1-10 U/mL thrombin or 1-10 $\mu \mathrm{M}$ PAR1 AP (not shown). As shown in Table 1, the thrombin-induced paranodal demyelination could be inhibited by hirudin, which blocks both the PAR recognition and thrombin active sites.
The thrombin-induced demyelinating effect was also impeded by the intracellular calcium chelator BAPTA-AM (Table 1). Thus, since the observed paranodal demyelination appeared to be calcium-related, we challenged nerve fibers with thapsigargin, a compound known to induce an increase in cytosolic $\mathrm{Ca}^{2+}$ with a mechanism different from the one elicited by the activation of the thrombin/PAR1 axis. In fact, thapsigargin raises the intracellular $\mathrm{Ca}^{2+}$ concentration by blocking the endoplasmic reticulum $\mathrm{Ca}^{2+}$ ATPase (SERCA) and activating plasma membrane $\mathrm{Ca}^{2+}$ channels ${ }^{25}$.

Similarly to thrombin $(100 \mathrm{U} / \mathrm{mL})$, thapsigargin induced a pronounced alteration in $\mathrm{S} 100 \mathrm{~b}$ and myelin distribution in nerve

Table 1. Percentage of paranodal demyelination in nerve fibers following PAR1 overactivation. Ex vivo nerve explants were treated with: thrombin $(1,10,100 \mathrm{U} / \mathrm{mL}), 100 \mathrm{U} / \mathrm{mL}$ hirudin + $100 \mathrm{U} / \mathrm{mL}$ thrombin, $1 \mu \mathrm{M}$ BAPTA AM $+100 \mathrm{U} / \mathrm{mL}$ thrombin; PAR1 AP $(1,10,100 \mu \mathrm{M}), 1 \mu \mathrm{M}$ BAPTA AM + $100 \mu \mathrm{M}$ PAR1 AP, $1 \mu \mathrm{M}$ SCH79797 + $100 \mu \mathrm{M}$ PAR1 AP. After $30 \mathrm{~min}, 1 \mathrm{~h}$ and $2 \mathrm{~h}$ of treatment samples were fixed, teased and stained by Sudan black. The percentage of nodes of Ranvier showing demyelination was calculated from 5 random fields per well, and the data are expressed as a mean percentage of 6 wells. Data are presented as mean \pm SEM.

\begin{tabular}{lccc} 
& 30 min & $1 \mathrm{~h}$ & $2 \mathrm{~h}$ \\
Thrombin (THR) & & & \\
0 & $5 \pm 3$ & $8 \pm 2$ & $12 \pm 4$ \\
$1 \mathrm{U} / \mathrm{mL}$ THR & $4 \pm 2$ & $7 \pm 3$ & $8 \pm 6$ \\
$10 \mathrm{U} / \mathrm{mL}$ THR & $6 \pm 3$ & $7 \pm 5$ & $12 \pm 5$ \\
$100 \mathrm{U} / \mathrm{mL}$ THR & $15 \pm 3^{*}$ & $30 \pm 5^{*}$ & $46 \pm 6^{*}$ \\
BAPTA AM + 100 U/mL THR & $6 \pm 2$ & $5 \pm 3$ & $11 \pm 4$ \\
Hirudin + 100 U/mL THR & $7 \pm 2$ & $10 \pm 4$ & $15 \pm 6$ \\
PAR 1 AP & & & \\
0 & $5 \pm 3$ & $8 \pm 2$ & $12 \pm 4$ \\
$1 \mu \mathrm{M}$ PAR 1 AP & $6 \pm 4$ & $11 \pm 5$ & $10 \pm 3$ \\
$10 \mu \mathrm{M}$ PAR 1 AP & $3 \pm 1$ & $9 \pm 5$ & $10 \pm 5$ \\
$100 \mu \mathrm{M}$ PAR 1 AP & $13 \pm 3^{*}$ & $25 \pm 4^{*}$ & $32 \pm 7^{*}$ \\
BAPTA AM + 100 $\mu$ M PAR 1 AP & $4 \pm 2$ & $7 \pm 4$ & $9 \pm 3$ \\
SCH79797+ 100 $\mu$ M PAR 1 AP & $8 \pm 4$ & $14 \pm 6$ & $18 \pm 7$ \\
\hline
\end{tabular}

${ }^{*} \mathrm{P} \leq 0.01$ respect to control.
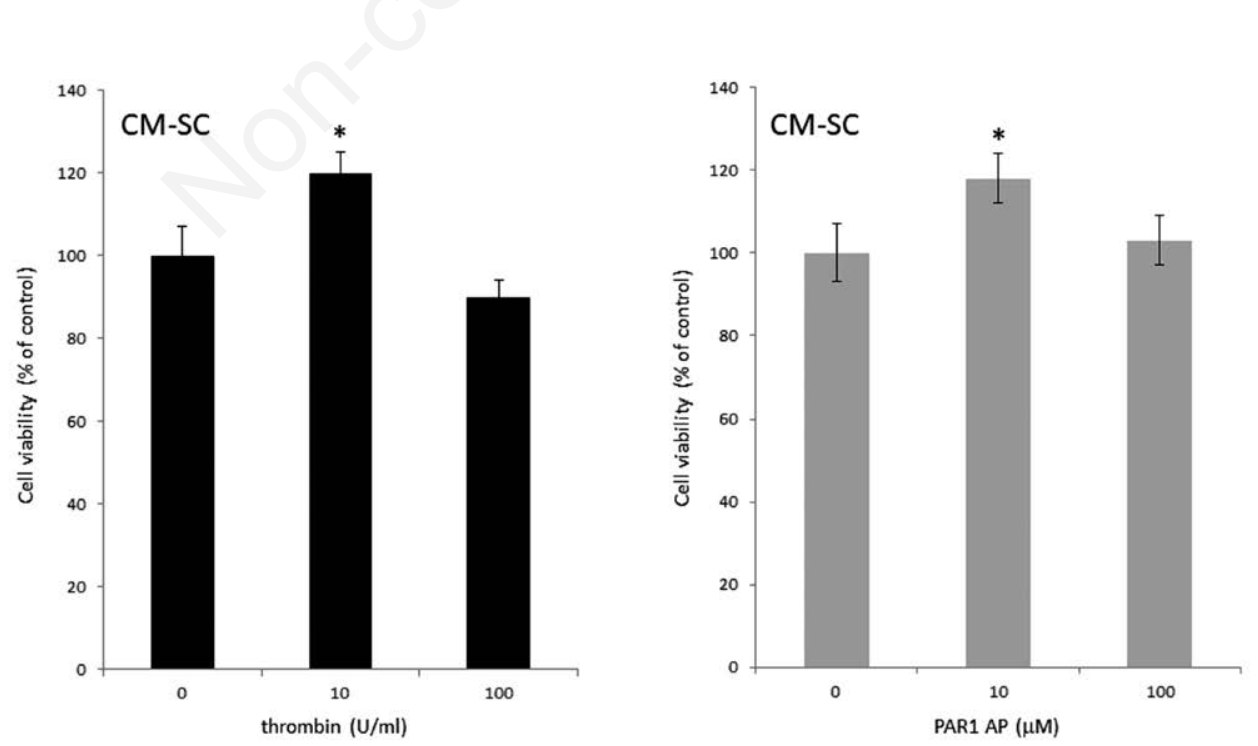

Figure 2. The conditioned medium (CM) from thrombin-treated Schwann cells (SC) does not affect PC12 cell viability. PC12 cells were exposed for 7 days to the $\mathrm{CM}$ of $\mathrm{SC}$ left untreated or treated with thrombin $(10$ and $100 \mathrm{U} / \mathrm{mL})$ and PAR1 AP $(10$ and $100 \mu \mathrm{M})$. Cell viability was evaluated by the MTT assay. Data are presented as mean \pm SEM of three independent experiments. ${ }^{*} \mathrm{P} \leq 0.01$ respect to the untreated control. 
A

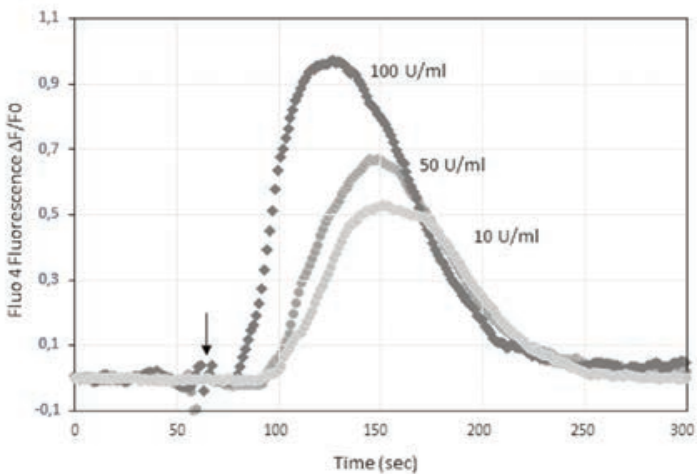

B

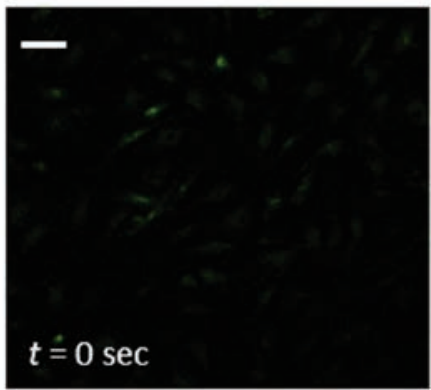

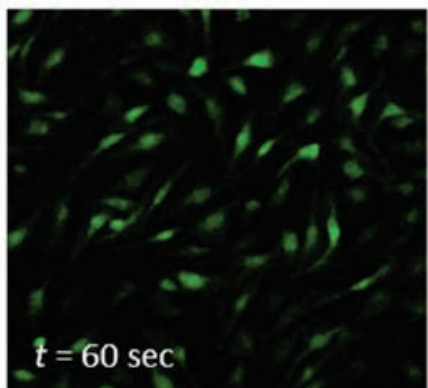
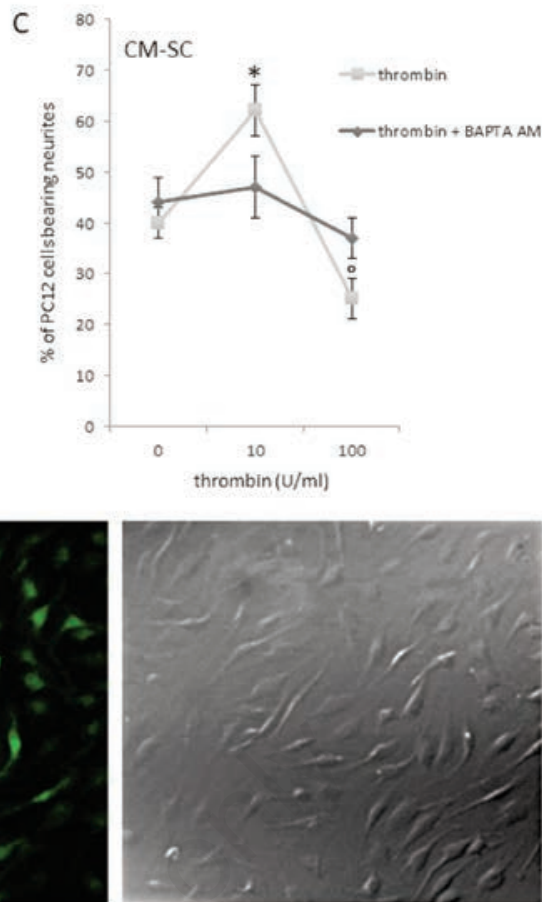

Figure 3. Thrombin dose-dependently induces an increase in intracellular $\mathrm{Ca}^{2+}$ levels in Schwann cells (SC). A) Representative tracings of the cytosolic $\mathrm{Ca}^{2+}$ indicator dye Fluo4 after application of different doses of thrombin $(10,50,100 \mathrm{U} / \mathrm{mL})$ to $\mathrm{SC}$; arrow points at the stimulus administration; tracings indicate the mean fluorescence value of all cells in one field and are indicative of three independent experiments. B) SC loaded with Fluo4 at time 0 and after $60 \mathrm{~s}$ from the application of $100 \mathrm{U} / \mathrm{mL}$ of thrombin; time 0 corresponds to the stimulus administration (arrow in A). Phase contrast is shown on the right; scale bar: $50 \mu \mathrm{m}$. C) PC12 cells were exposed for 7 days to the conditioned medium (CM-SC) from SC treated with 10 and $100 \mathrm{U} / \mathrm{mL}$ of thrombin alone or in combination with $1 \mu \mathrm{M}$ BAPTA AM. Data are presented as mean $\pm S E M .{ }^{\circ} \mathrm{P} \leq 0.05$; ${ }^{*} \mathrm{P} \leq \mathbf{0 . 0 1}$ respect to samples left untreated or treated with vehicle alone.
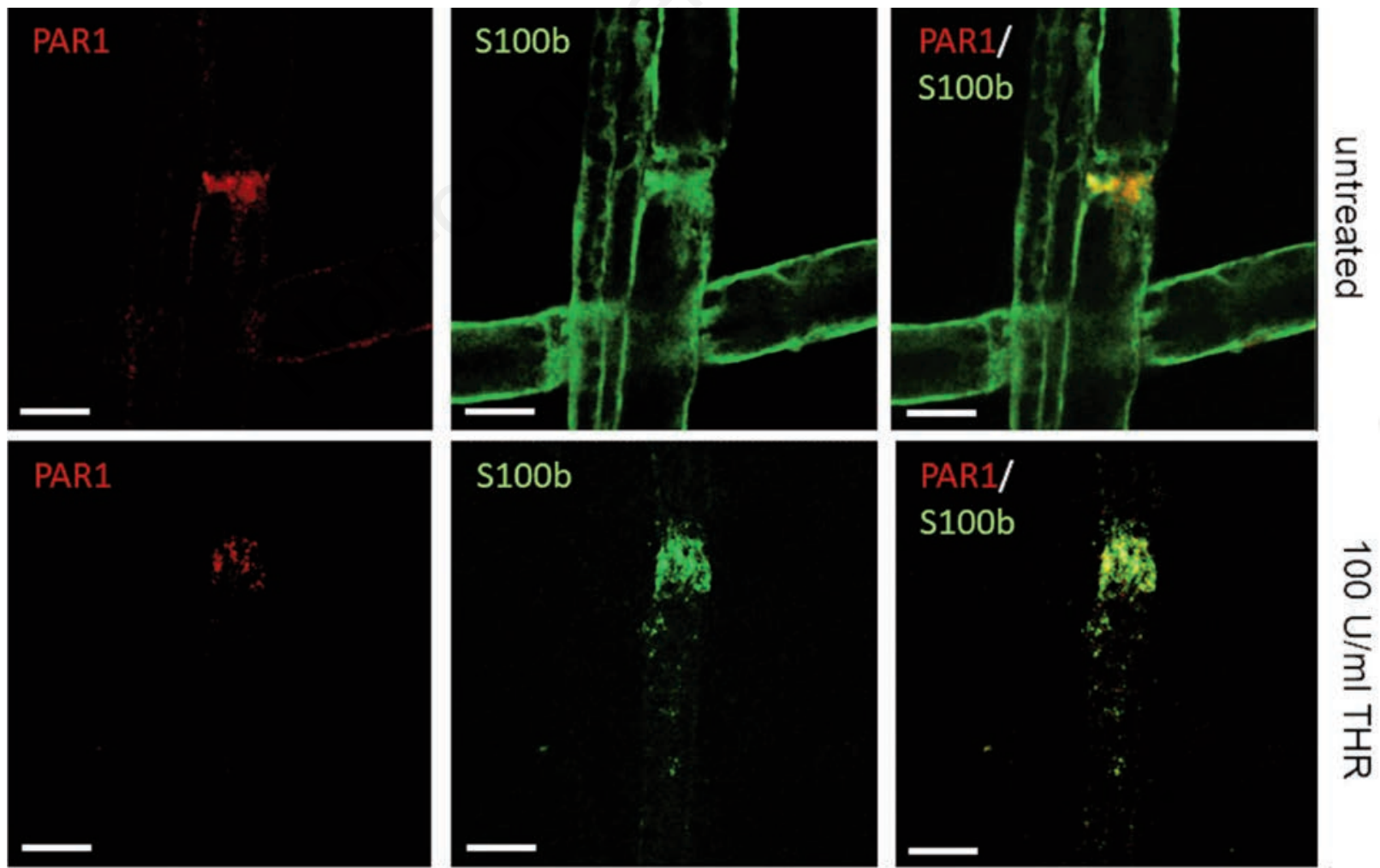

Figure 4. Double immunofluorescence staining for PAR1 and S100b of fibers from ex vivo nerve explants after 2-h culture. A) PAR1 appears highly expressed at the level of the nodes of Ranvier in untreated control. B) After treatment with $100 \mathrm{U} / \mathrm{mL}$ of thrombin both PAR1 and S100b are scattered and in clusters. Scale bar: $10 \mu \mathrm{m}$. 
A

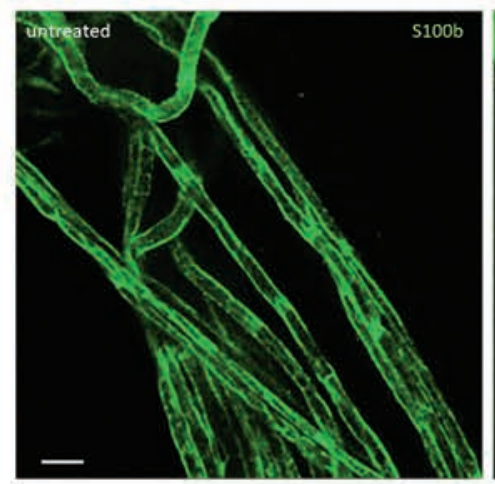

C

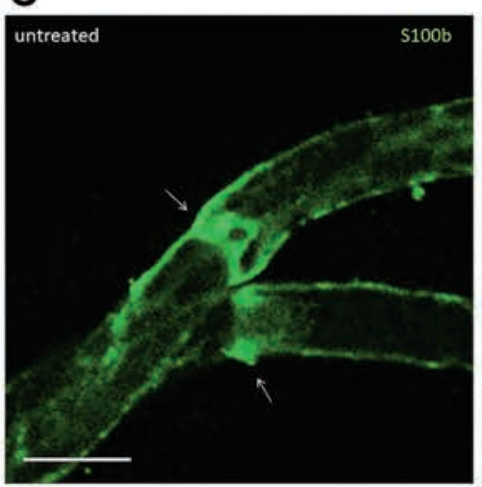

D

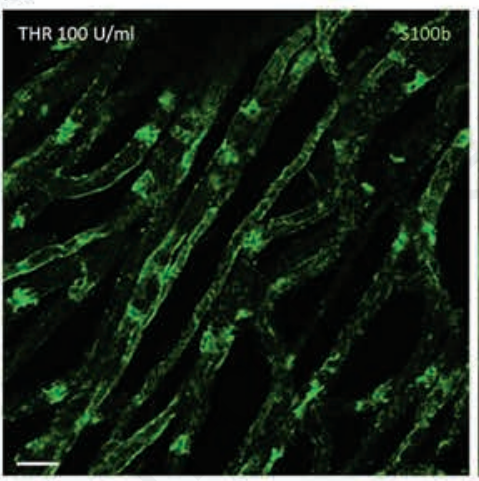

F

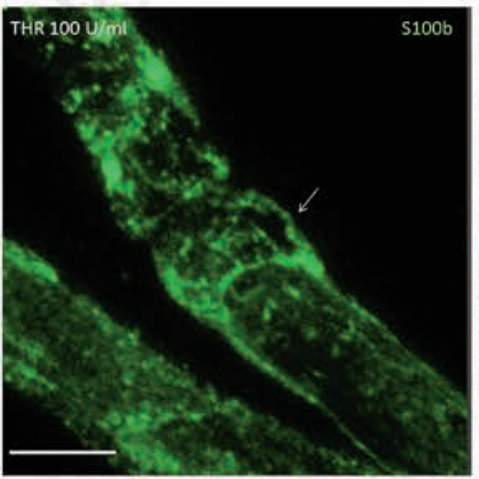

B
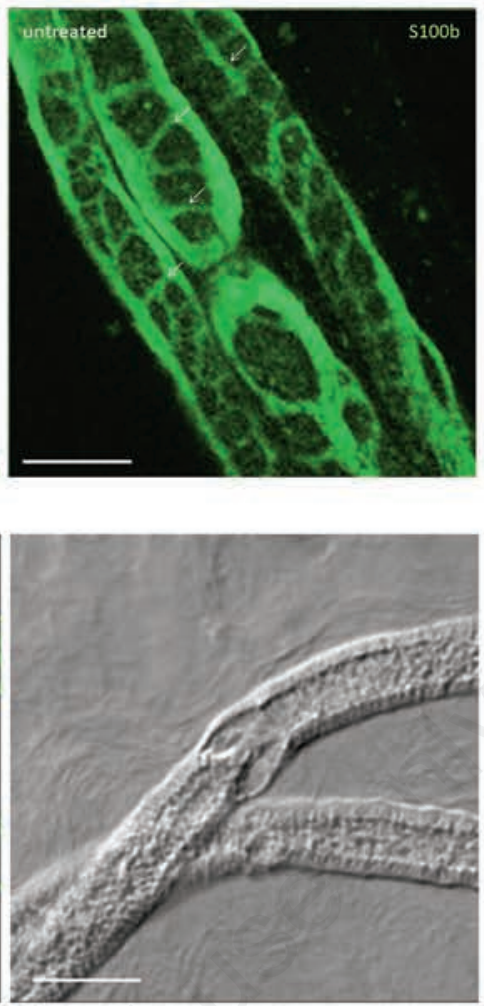

E
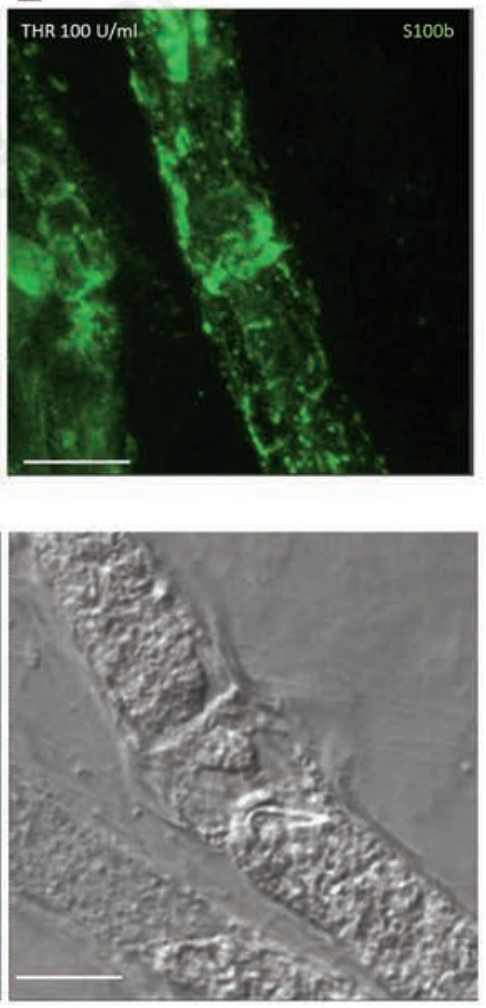

Figure 5. Immunofluorescence staining of fibers from ex vivo nerve explants for the SC cytosolic marker S100b. Thrombin-treatment alters the morphology of both the Cajal bands and the Schmidt-Lanterman incisures (SLI). A) Control fibers left untreated for $2 \mathrm{~h}$; scale bar: $20 \mu \mathrm{m}$. B) Control fibers at higher magnification showing a node of Ranvier and the presence of Cajal bands (arrows); scale bar: $10 \mu \mathrm{m}$. C) Schmidt-Lanterman incisures (arrows) in control fibers left untreated for $2 \mathrm{~h}$; phase contrast image on the right; scale bar: $10 \mu \mathrm{m}$. D) Nerve fibers treated for $2 \mathrm{~h}$ with $100 \mathrm{U} / \mathrm{mL}$ of thrombin (THR); scale bar: $20 \mu \mathrm{m}$. E) Nerve fibers treated for $2 \mathrm{~h}$ with 100 $\mathrm{U} / \mathrm{mL}$ of thrombin (THR) at higher magnification showing the highly disorganized architecture of the Cajal bands; scale bar $10 \mu \mathrm{m}$. F) Dilation of a Schmidt-Lanterman incisure (arrow) in nerve fibers treated for $2 \mathrm{~h}$ with $100 \mathrm{U} / \mathrm{mL}$ of thrombin (THR); phase contrast image on the right; scale bar: $10 \mu \mathrm{m}$. 
fibers. When administered to ex vivo nerve explants this compound determined extensive paranodal demyelination of nerve fibers $(57 \pm 6 \%$ at $2 \mathrm{~h}$ ) with concurrent enlargement of the SLI and disappearance of Cajal bands. In addition, in thapsigargin-treated samples demyelination appeared also in vast areas of the internodes (Figure 7).

\section{Discussion}

In this paper we show that the activation of the thrombin/PAR1 axis in SC profoundly affects two major properties of these cells that is their ability to promote neuritogenesis and their capacity to maintain the integrity of the nodes of Ranvier.

When treated with low levels of thrombin SC in culture show an enhanced ability to release factors promoting PC12 neurite extension. This effect can be blocked by the administration of hirudin, which inhibits the thrombin proteolyic activity, and it can be reproduced by a specific PAR1 agonist peptide. These results are consistent with our previous data indicating that the activation of PAR1 induces the release from SC of molecules, which favor neuronal survival and neurite extension such as decorin and MIF. ${ }^{14}$ Although it would be improper to directly translate these findings in vivo, these data are in line with results obtained in vivo where thrombin at low concentration was demonstrated to favor nerve regeneration. ${ }^{9}$ As mentioned above, peripheral nerve damage is accompanied by the increase in thrombin activity at the site of injury. ${ }^{5,6}$ Thrombin activity was also found to be increased early in the clinical course of experimental autoimmune neuritis (EAN) in rat sciatic nerve. ${ }^{2}$ In our model system SC treated with high levels of thrombin $(100 \mathrm{U} / \mathrm{mL})$ showed a reduced capacity of promoting PC12 neurite extension respect to controls. This effect appeared not related to the release of cytotoxic molecules from thrombintreated SC primary cultures. The different effect exerted by thrombin in cultures at low and high doses is not surprising since in other systems this protease was reported to display different actions according to its concentration. ${ }^{11}$

We observed divergent effects of low and high levels of
A
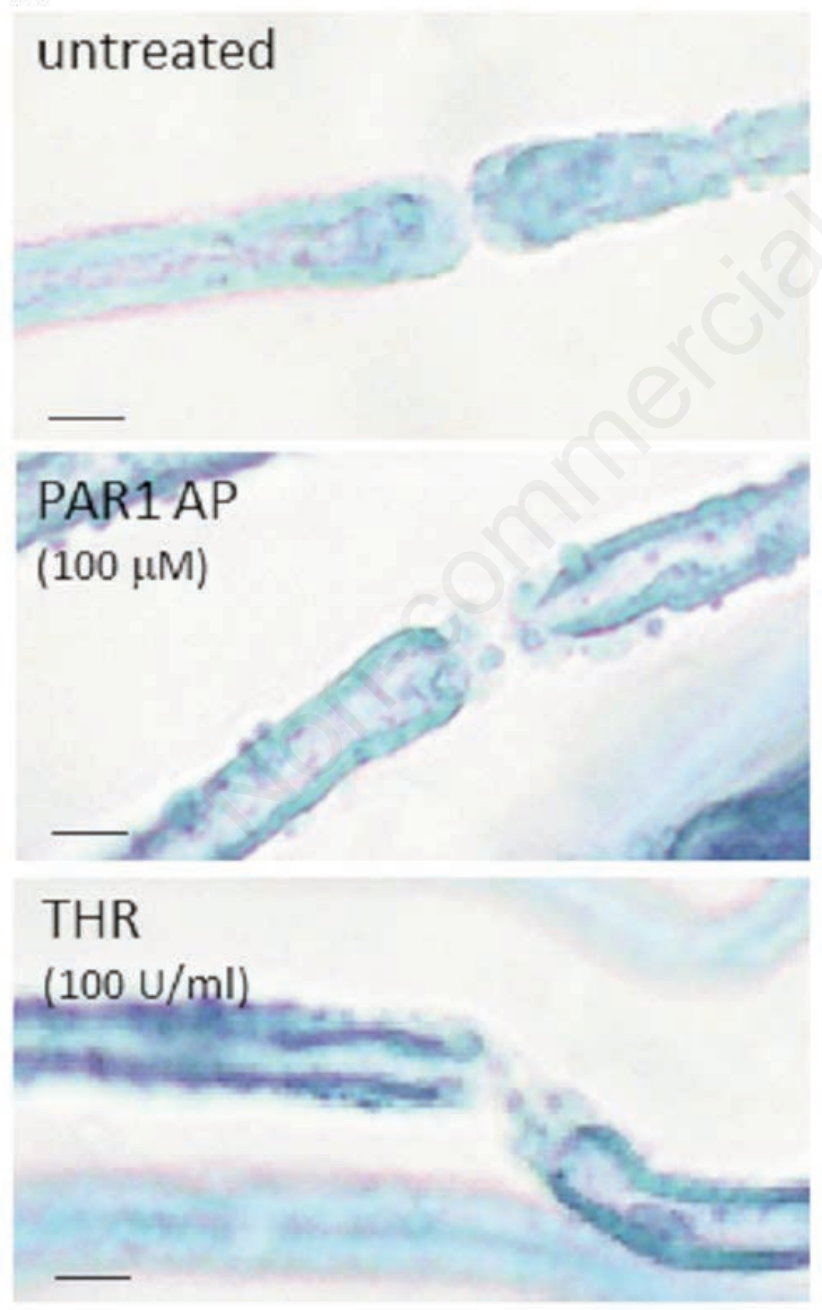

B
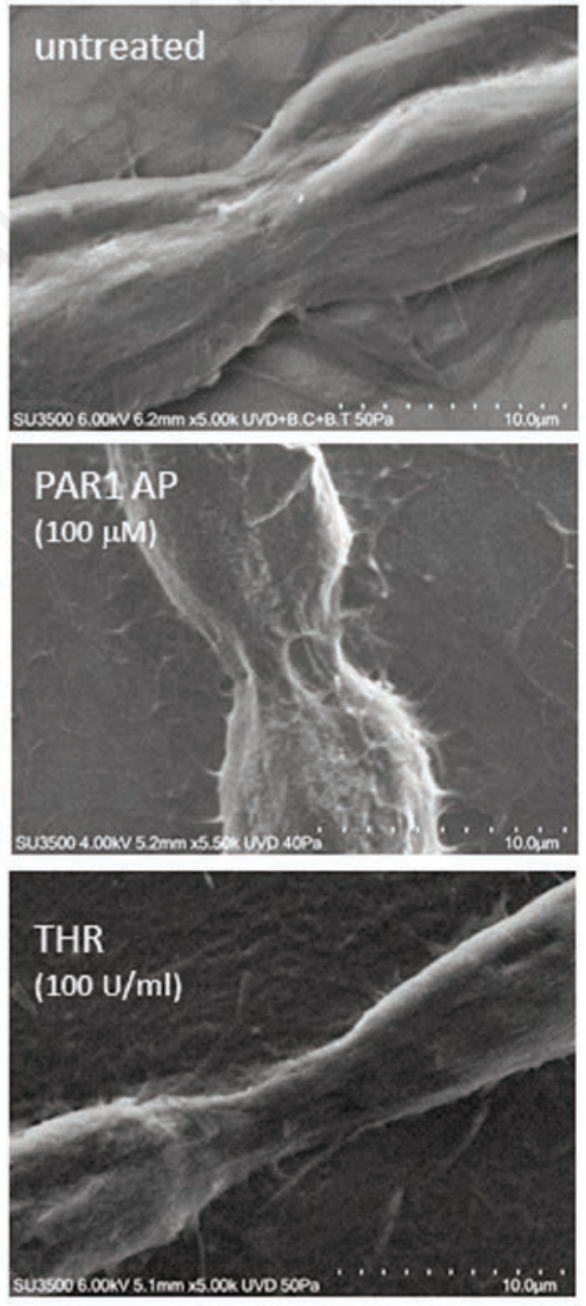

Figure 6. PAR1 overactivation determines in ex vivo nerve explants paranodal demyelination associated to a displacement of SC at the level of the nodes. A) Nerve fibers treated for $2 \mathrm{~h}$ with $100 \mathrm{U} / \mathrm{mL}$ of thrombin (THR) or $100 \mu \mathrm{m}$ PAR1 AP observed by Sudan black staining are characterized by demyelination and myelin fragmentation at the level of the paranodes; scale bars: $10 \mu \mathrm{m}$. B) Nerve fibers treated for $2 \mathrm{~h}$ with $100 \mathrm{U} / \mathrm{mL}$ of thrombin (THR) or $100 \mu \mathrm{m}$ PAR1 AP observed by VP-SEM show displacement of SC in the nodal region and elongated nodes; scale bars: $10 \mu \mathrm{m}$. 
A

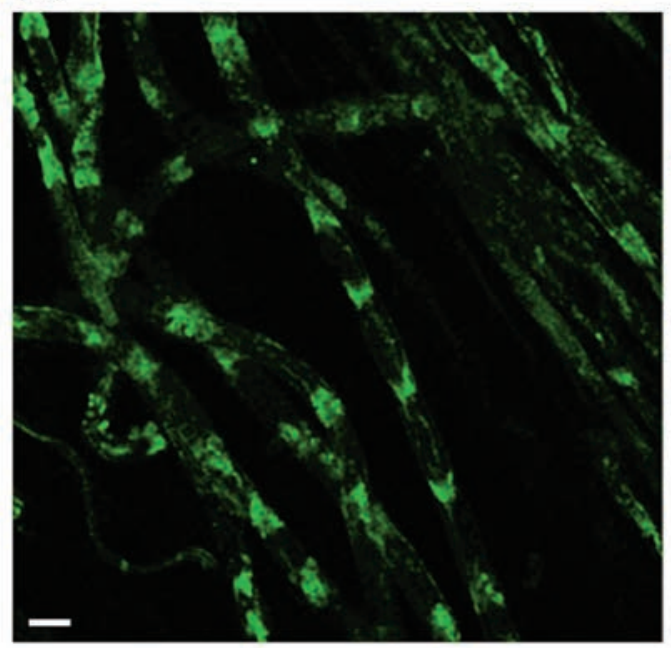

B

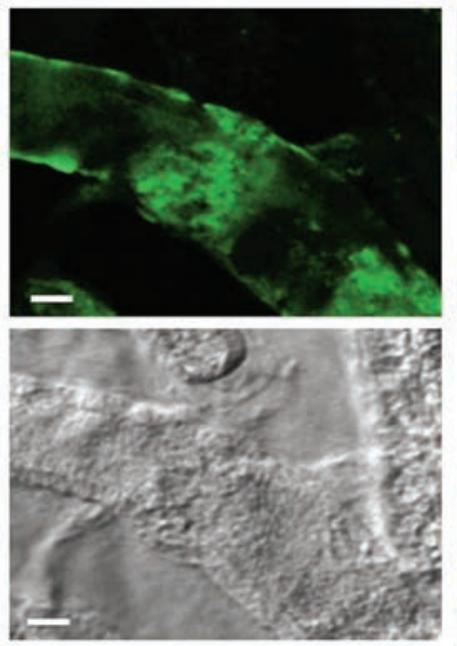

C

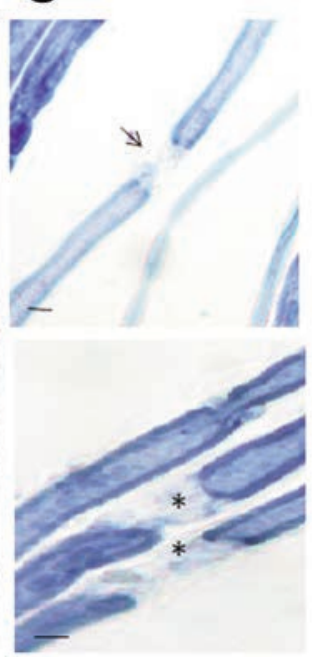

Figure 7. Thapsigargin promotes extensive demyelination in nerve fibers. Ex vivo nerve explants were treated for $2 \mathrm{~h}$ with thapsigargin and then stained for S100b $(A, B)$ and with Sudan black $(C)$. In nerve fibers thapsigargin, similarly to thrombin $(100 \mathrm{U} / \mathrm{mL})$, determines the disappearance of the Cajal bands and the dilation of the Schmidt-Lanterman incisures $(A, B)$. Demyelination is observed not only at the paranodal region (arrow) but also in the internodal areas (asterisks) (C). Scale bars: A,C) $10 \mu \mathrm{m} ; \mathrm{B}) 20 \mu \mathrm{m}$.

thrombin on SC also in sciatic nerve ex vivo explants. In this model system although the nerve is transected the three-dimensional relationship between SC and the axon is mainly maintained. Low levels of thrombin in this model did not determine any evident modification in the morphology of SC and in particular of the nodes. Conversely, high levels of thrombin $(100 \mathrm{U} / \mathrm{mL})$ or PAR1 AP (100 $\mu \mathrm{M})$ induced a profound rearrangement of SC and in particular the disappearance of the Cajal bands. Interestingly, a similar pattern of alteration of the Cajal bands is observed after chronic nerve compression. ${ }^{27}$ Studies using periaxin-null mice indicate that the Cajal bands facilitate the microtubule-based transport of proteins and organelles in SC and aberrations in their architecture compromises myelin maintenance. ${ }^{28}$ Actually, our data show that nerve fibers treated with high levels of PAR1 agonists present evident signs of demyelination at the level of the paranodes. It is notable that PAR1 is mostly expressed on the microvilli of the SC, that is in close proximity to the paranodes..$^{14,20}$ In addition, thrombin (100-200 $\mathrm{U} / \mathrm{mL})$ and PAR1 AP (150-300 $\mu \mathrm{M})$ cause a conduction failure in sciatic nerve within 30 min of application. ${ }^{20}$

Our data indicate that the observed paranodal demyelination induced after PAR1 overactivation is calcium-mediated. In connection with this result, elevation of intracellular $\mathrm{Ca}^{2+}$ levels has been reported to induce myelin basic protein (MBP) network disassembly and myelin vesiculation in CNS. ${ }^{29}$ Besides, in ischemia myelin is damaged in a calcium-dependent manner, abolishing action potential propagation, ${ }^{30-32}$ and specific thrombin inhibitors were shown to reduce neurological deficit in models of middle cerebral artery occlusion. ${ }^{33}$ The beneficial effect of thrombin inhibition was recently reported to occur in EAN, ${ }^{25}$ and diabetic neuropathy ${ }^{34}$ indicating the pathogenic importance of this pathway also in the PNS.

Our results obtained with high levels of thrombin in SC cultures and ex vivo nerve explants can be reproduced by PAR1 AP and inhibited by the specific PAR1 antagonist SCH79797 indicating the involvement of PAR1 in these processes. Nevertheless, the possibility of activation and transactivation of other members of the PAR family cannot be completely ruled out. In particular, thrombin in adequate concentrations is known to activate the receptor for trypsin PAR2 $2^{35}$ and the low-affinity thrombin receptor PAR $4 .{ }^{36}$ However, in our SC cultures while thrombin and PAR1 AP dose-dependently induce a consistent rise in cytosolic $\mathrm{Ca}^{2+}$, the specific agonist peptides for PAR2 and PAR4 determine only negligible modifications of the intracellular $\mathrm{Ca}^{2+}$ levels (unpublished observations). Our data contribute towards considering thrombin, which appears deregulated at sites of PNS injury a possible novel therapeutic target. Potentially a pharmacological reduction of its excessive activity at the level of nerve lesions could circumvent the demyelinating properties of this protease and restore the SC neurotrophic activities. Nevertheless, the complete pathways, which underlie thrombin deleterious or protective effect in PNS, need further investigation before considering possible therapeutic applications.

\section{Acknowledgments}

This work was supported by grants from Sapienza University to CF (RM118164328DF7F2 and RM11916B88BF39BB). The authors thank Diane Sherman and Peter J. Brophy for the gift of the OX-42 hybridoma cell line.

\section{References}

1. Jessen KR, Mirsky R. The success and failure of the Schwann cell response to nerve injury. Front Cell Neurosci 2019;11;13:33.

2. Li H, Terenghi G, Hall SM. Effects of delayed re-innervation on the expression of c-erbB receptors by chronically denervated rat Schwann cells in vivo. Glia 1997;20:333-47.

3. Rönkkö H, Göransson H, Siironen P, Taskinen HS, Vuorinen V, Rönkkö M. The capacity of the distal stump of peripheral nerve to receive growing axons after two and six months denervation. Scand J Surg 2011; 100:223-9. 
4. Jonsson, S, Wiberg R, McGrath AM, Novikov LN, Wiberg M, Novikova LN, et al. Effect of delayed peripheral nerve repair on nerve regeneration, Schwann cell function and target muscle recovery. PLoS One 2013;8:e56484.

5. Bushi D, Gera O, Kostenich G, Shavit-Stein E, Weiss R, Chapman J, et al. A novel histochemical method for the visualization of thrombin activity in the nervous system. Neuroscience 2016;320:93-104.

6. Gera O, Shavit-Stein E, Bushi D, Harnof S, Shimon MB, Weiss $\mathrm{R}$, et al. Thrombin and protein $\mathrm{C}$ pathway in peripheral nerve Schwann cells. Neuroscience 2016;339:587-98.

7. Henderson JM, Stein SF, Kutner M, Wiles MB, Ansley JD, Rudman D. Analysis of twenty-three plasma proteins in ascites. The depletion of fibrinogen and plasminogen. Ann Surg 1980;192:738-42.

8. Gera O, Bushi D, Ben Shimon M, Artan-Furman A, Harnof S, Maggio N, et al. Local regulation of thrombin activity by factor $\mathrm{Xa}$ in peripheral nerve Schwann cells. Neuroscience 2018;371:445-54.

9. Balezina OP, Gerasimenko NY, Dugina TN, Strukova SM. Study of neurotrophic activity of thrombin on the model of regenerating mouse nerve. Bull Exp Biol 2005;139:4-6.

10. Lee P, Spector JG, Derby A, Roufa DG. Effects of thrombin and protease nexin-1 on peripheral nerve regeneration. Ann Otol Rhinol Laryngol 1998;107:61-9.

11. Striggow F, Riek M, Breder J, Henrich-Noack P, Reymann $\mathrm{KG}$, Reiser G. The protease thrombin is an endogenous mediator of hippocampal neuroprotection against ischemia at low concentrations but causes degeneration at high concentrations. Proc Natl Acad Sci USA 2000;97:2264-9.

12. Coughlin SR. Protease-activated receptors in hemostasis, thrombosis and vascular biology. J Thromb Haemost 2005;3: 1800-14.

13. Bampton ET, Taylor JS. Effects of Schwann cell secreted factors on PC12 cell neuritogenesis and survival. J Neurobiol 2005;63:29-48.

14. Pompili E, Fabrizi C, Somma F, Correani V, Maras B, Schininà $\mathrm{ME}$, et al. PAR1 activation affects the neurotrophic properties of Schwann cells. Mol Cell Neurosci 2017;79:23-33.

15. Hollenberg MD, Mihara K, Polley D, Suen JY, Han A, Fairlie $\mathrm{DP}$, et al. Biased signalling and proteinase-activated receptors (PARs): targeting inflammatory disease. Br J Pharmacol 2014; 171:1180-94.

16. Macfarlane SR, Seatter MJ, Kanke T, Hunter GD, Plevin R. Proteinase-activated receptors. Pharmacol Rev 2001;5):245-82.

17. Pompili E, Fabrizi C, Fornai F, Fumagalli L. Expression and role of protease-activated receptor 1 in glial cells of central and peripheral nervous system. J Neural Transm 2019;126:1259-71.

18. Burda JE, Radulovic M, Yoon H, Scarisbrick IA. Critical role for PAR1 in kallikrein 6-mediated oligodendrogliopathy. Glia 2013;61:1456-70.

19. Yoon H, Radulovic M, Drucker KL, Wu J, Scarisbrick IA. The thrombin receptor is a critical extracellular switch controlling myelination. Glia 2015;63:846-59.

20. Shavit E, Beilin O, Korczyn AD, Sylantiev C, Aronovich R, Drory VE, et al. Thrombin receptor PAR-1 on myelin at the node of Ranvier: a new anatomy and physiology of conduction block. Brain 2008;131:1113-22.

21. Fabrizi C, Kelly BM, Gillespie CS, Schlaepfer WW, Scherer SS, Brophy PJ. Transient expression of the neurofilament proteins NF-L and NF-M by Schwann cells is regulated by axonal contact. J Neurosci Res 1997;50:291-9.

22. Uggenti C, De Stefano ME, Costantino M, Loreti S, Pisano A, Avallone B, et al. M2 muscarinic receptor activation addresses Schwann cell differentiation and myelin organization. Dev Neurobiol 2014;74:676-91.

23. Fabrizi C, Businaro R, Lauro GM, Starace G, Fumagalli L. Activated alpha2macroglobulin increases beta-amyloid (2535)-induced toxicity in LAN5 human neuroblastoma cells. Exp Neurol 1999;155:252-9.

24. Correani V, Di Francesco L, Cera I, Mignogna G, Giorgi A, Mazzanti $\mathrm{M}$, et al. Reversible redox modifications in the microglial proteome challenged by beta amyloid. Mol Biosyst 2015;11:1584-93.

25. Michelangeli F, East JM. A diversity of SERCA Ca2+ pump inhibitors. Biochem Soc Trans. 2011;39:789-97.

26. Shavit-Stein E, Aronovich R, Sylantiev C, Gera O, Gofrit SG, Chapman J, et al. Blocking thrombin significantly ameliorates experimental autoimmune neuritis. Front Neurol 2019 9:1139.

27. Gupta R, Nassiri N, Hazel A, Bathen M, Mozaffar T. Chronic nerve compression alters Schwann cell myelin architecture in a murine model. Muscle Nerve 2012;45:231-41.

28. Court FA, Sherman DL, Pratt T, Garry EM, Ribchester RR, Cottrell DF, et al. Restricted growth of Schwann cells lacking Cajal bands slows conduction in myelinated nerves. Nature 2004;431:191-5.

29. Weil MT, Möbius W, Winkler A, Ruhwedel T, Wrzos C, Romanelli E, et al. Loss of myelin basic protein function triggers myelin breakdown in models of demyelinating diseases. Cell Rep 2016;16:314-22.

30. Stys PK, Ransom BR, Waxman SG, Davis PK. Role of extracellular $\mathrm{Ca} 2+$ in anoxic injury of central white matter. Proc Natl Acad Sci USA 1990;87:4212-6.

31. Micu I, Jiang Q, Coderre E, Ridsdale A, Zhang L, Woulfe J, et al. NMDA receptors mediate calcium accumulation in myelin during chemical ischaemia. Nature 2006;439:988-92.

32. Hamilton NB, Kolodziejczyk K, Kougioumtzidou E, Attwell D. Proton-gated $\mathrm{Ca}(2+)$-permeable TRP channels damage myelin in conditions mimicking ischaemia. Nature 2016;529:523-7.

33. Lyden P, Pereira B, Chen B, Zhao L, Lamb J, Lei IF, et al. Direct thrombin inhibitor argatroban reduces stroke damage in 2 different models. Stroke 2014;45:896-9.

34. Shavit-Stein E, Aronovich R, Sylantiev C, Gofrit SG, Chapman J, Dori A. The role of thrombin in the pathogenesis of diabetic neuropathy. PLoS One 2019;14:e0219453.

35. Mihara K, Ramachandran R, Saifeddine M, Hansen KK, Renaux B, Polley D, et al. Thrombin-mediated direct activation of proteinase-activated receptor-2: Another target for thrombin signaling. Mol Pharmacol 2016;89:606-14.

36. Geisler T. PAR-4 - The PARagon of protease-activated receptors? Int J Cardiol 2018;252:167-8.

Received for publication: 9 January 2020. Accepted for publication: 13 March 2020.

This work is licensed under a Creative Commons Attribution-NonCommercial 4.0 International License (CC BY-NC 4.0).

(C) Copyright: the Author(s), 2020

Licensee PAGEPress, Italy

European Journal of Histochemistry 2020; 64:3109

doi:10.4081/ejh.2020.3109 